\title{
A CONTRIBUTION TO THE PREDICTION OF SLUSH AVALANCHES
}

by

\author{
ERIK HestNes
}

Norwegian Geotechnical Institute, P O Box 40 Tảsen, N-0801 Oslo 8, Norway

\section{ABSTRACT}

Slush avalanches, primarily known from uninhabited arctic and mountainous regions, every year cause damage to man and property in Norway. Seeking objective criteria to identify their hazard zones, and methods for their prediction and control, the Norwegian Geotechnical Institute (NGI) has started a research program on these topics.

Thirty-four slush avalanches with known locations of crown surface have been investigated with regard to geomorphic and climatic characteristics. Starting zones, crown surfaces and tracks were classified according to geomorphic conditions important to avalanche release and motion.

Weak cohesionless snowpacks of coarse grains, and hard layers or crusts of ice in snow cover or on the ground, are critical conditions for slush avalanche release. Intense rain, falling on cohesionless new snow on these substrata, is the most striking feature of current weather situations.

The main starting zones were drainage channels, sloping bogs, depressions and open fields. Channel-like, scar-like or bowl-like features appeared in the snow cover due to avalanche release. Three main types of release were identified: 1) Sudden release from crown surface, 2) drainage of snow-embanked, water-saturated snowfields through narrow outlets and 3) rapid headward growth from first point of release.

Enlargements and confinements along the avalanche tracks were caused by distinctly defined features in the tracks.

\section{INTRODUCTION}

Slush avalanches, ie rapid mass-movement of water-saturated snow, have primarily been reported from uninhabited arctic and mountainous areas. Main works on the topic are presented by Luckman (1977), Nobles (1966), Rapp (1960) and Raup (1971).

In Norway slush avalanches every year cause damage to man, housing, communication lines etc, and they are of critical concern in land-use planning (Figure 1). In 1983 the Norwegian Geotechnical Institute started a research program on slush avalanches. The main purpose of the project is to elaborate on principles and techniques to identify areas subjected to these avalanches, and methods for their prediction and control. The present program is focused on quantitative and qualitative aspects of drainage basin, starting zone and track of the avalanches and the climatic parameters influencing weather and snow conditions, as this forms the basis of most techniques for evaluation of avalanche sites and hazards. Thirty-four slush avalanches with known location of crown surface, ie top fracture surface, have been investigated. Most of them are dealt with separately in consultant reports by NGI during the last five years.

The main sources of information of the events have been people involved, other eyewitnessses, and police and newspaper reports. Avalanche paths and drainage basins were studied by interpretation of aerial photographs and comprehensive field work, and accurately drawn on maps of scale 1:5000 with contour interval $5 \mathrm{~m}$. Maps of scale 1:1 000 were used when

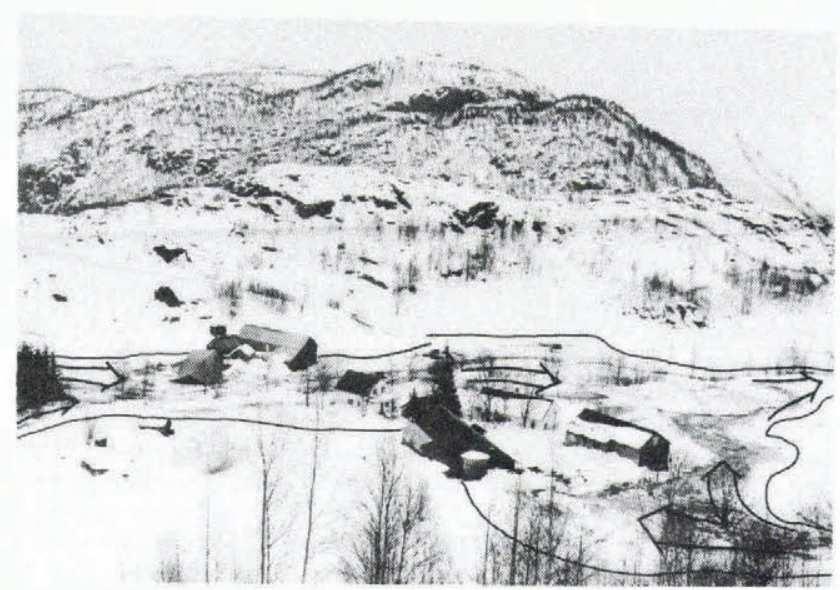

Fig.1. Slush avalanches at Hjorteland, Suldal, 3 March 1979. The avalanche from the left, which destroyed 4 buildings, was released at an elevation of $40 \mathrm{~m}$ above the farm yard. Average gradient of track was $12.5^{\circ}$. The avalanche from the right killed one person in the farmhouse to the right. (Photography by K. Strand)

available. The climatic conditions of snow cover, ground surface and drainage were analysed using local climatic data from the Norwegian Meteorological Institute (NMI), supplemented with on-site records. Basic data were air temperature, precipitation and snow cover recordings of the winter, and current weather situations.

\section{GEOMORPHIC FEATURES OF SLUSH AVALANCHE TERRAIN}

Field observations regarding starting zones, crown surfaces and tracks are summarized in Table 1.

Starting zones were most frequently located in small streams and brooks. The majority of the drainage channels were periodically dry, and some had an almost invisible course through pasture or sparsely forested terrain. Other characteristic release areas were open fields and gently sloping shallow depressions and bogs. The bogs were wet with smooth and grassy surfaces. The depressions also had high water levels, whereas the open fields were well drained. Both open fields and depressions, however, accumulated water from rather large areas. Five of the starting zones were influenced by man due to blocked drainage or uncontrolled outlets of drainage pipes.

Three major morphological types of starting zones appeared in the snow cover due to slush avalanche release (Figure 2). Linear (channel) zones with almost pointlike apexes were typical of sites with drainage channels. The length of crown surface was sometimes less than $2 \mathrm{~m}$. Scar-like zones and bowl-like zones with narrow outlets were formed on sites with open fields, bogs and depressions. The length of the crown for these two categories ranged between 10 and $100 \mathrm{~m}$.

The main geomorphic characteristics observed at 


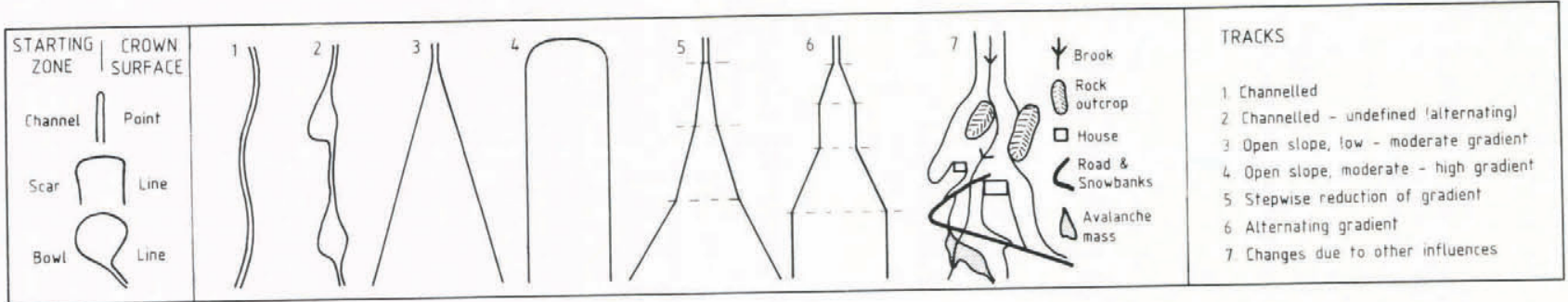

Fig.2. Major morphological types of starting zones and tracks opened in snow cover.

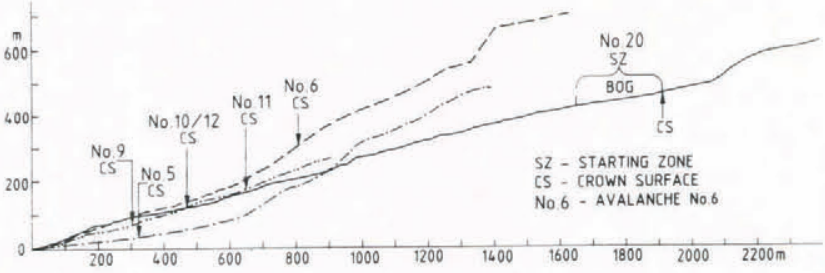

Fig.3. Profiles of 4 drainage basins. The gradient of the avalanche paths and location of the crown surfaces/starting zones vary greatly.

the crown surface are listed in Table 1. In drainage channels, crown surfaces were normally located either at sloping rock surfaces or at local drops in inclination associated with irregularities in ground conditions. The four sites with higher gradient downslope from the crown were also associated with somewhat similar and distinct local features in the channels.

The environs of 19 starting zones and tracks (ie approximately $60 \%$ of the sample) were cultivated land,

TABLE 1. SLUSH AVALANCHES - GEOMORPHIC FEATURES

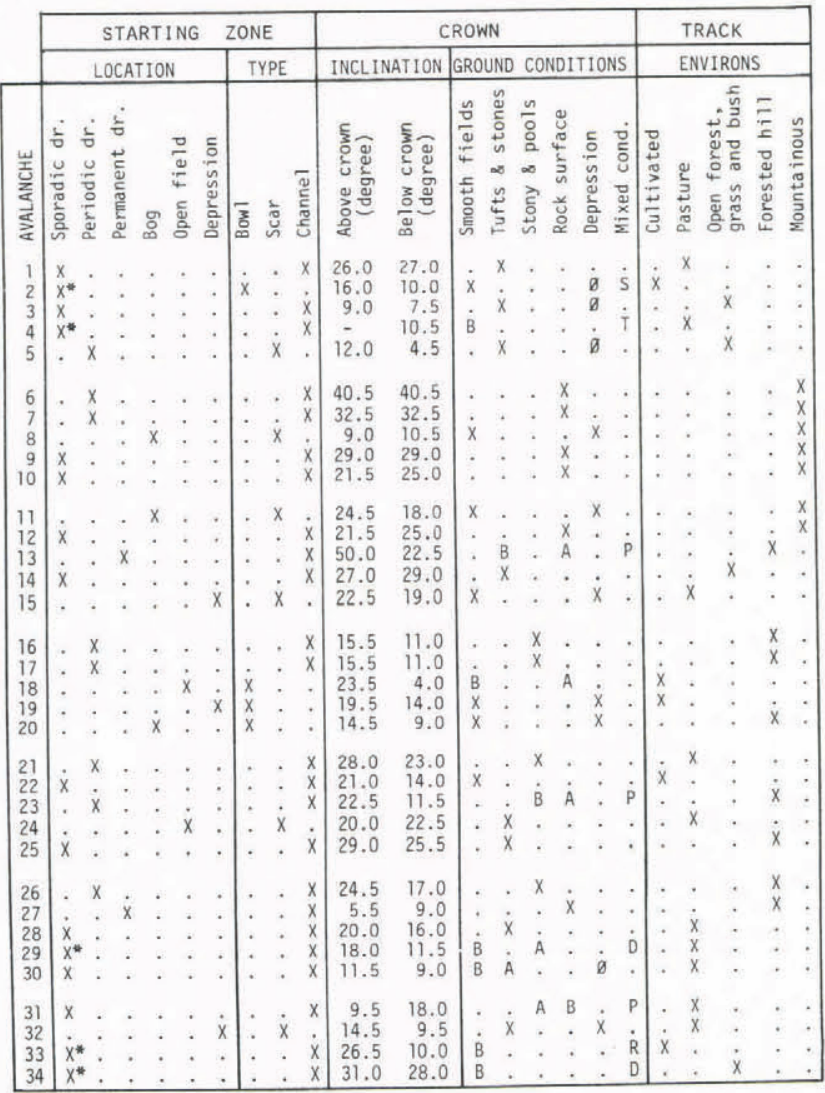
dr. - drainage; * - man-made influence; A, B - Above/Below crown; P - Pool pasture and open forest with grass and bush vegetation. This is also reflected in the ground conditions at the crown surfaces (Table 1). The eight slush avalanches with starting zones on forested hillsides had the most variable ground conditions at the crown surfaces, in the starting zones and along the tracks. The remaining seven avalanches were released in almost treeless mountainous terrain either on sloping bogs or rock surfaces, and had much the same environs along their tracks (Table 1). All except two of the avalanches originating on mountain or hillside, continued on to cultivated land in the lower part of the track.

Starting zones were located at almost every level within the drainage basins, and also at different levels and ground conditions in the same path profile (Figure 3). The average inclination from the crown to the bottom boundary of the main accumulation of slush, varied between $5^{\circ}$ and $20^{\circ}$, the mean gradient of the paths being $12.5^{\circ}$. The inclination, however, varied locally and of ten abruptly, in smaller or larger steps. This is true especially of tracks originating on forested hillsides and mountain sides. In addition, the direction of the main drainage channel often changes abruptly many times down an avalanche track.

Most of the avalanche tracks could be classified according to one of the six major morphological characters illustrated in Figure 2. A few tracks, however, had mixed characteristics. Local topographic forms, houses, roads, vegetation and accumulations of avalanche mass of ten affected these main types. Man-made features influenced especially the lower parts of the tracks and the runout zones.

Enlargement of the avalanche tracks was mainly caused by decrease in inclination. Change in drainage direction caused enlargement if the tracks were not strongly canalized. Other factors, eg local topographical forms and snow conditions, influenced enlargement both for increasing and decreasing inclination (Figure 4).

Confinement of the tracks occurred both with decrease and increase in inclination and was caused by a wide range of factors (Figure 4). Conf inement on decreasing downslope gradient was created mostly by local topography, buildings and snow banks along roads, while confinement on increasing gradient was also caused by the change in inclination itself and by local accumulations of avalanche mass.

Both enlargement and confinement of the slush avalanche tracks were located at distinctly defined features in the tracks.

\section{WINTER AND CURRENT WEATHER SITUATIONS}

The slush avalanches investigated occurred during the period December to April, and different climatic districts of Norway were represented. Eight avalanche situations were specially studied, regarding the effects both of winter and of current weather situations. These were also compared with the long range statistical recordings from the NMI observation stations of the avalanche prone districts (see Nord $\phi$ and Hjortnaes 1966, and Barthel and others 1981).

Meteorological conditions prior to the eight avalanche situations were of two quite different types. Four periods were characterized by frozen ground and temperatures below $0^{\circ} \mathrm{C}$ from the beginning of the winter season until a few days before avalanche release (Figure 5). The snowfall during these periods varied, 


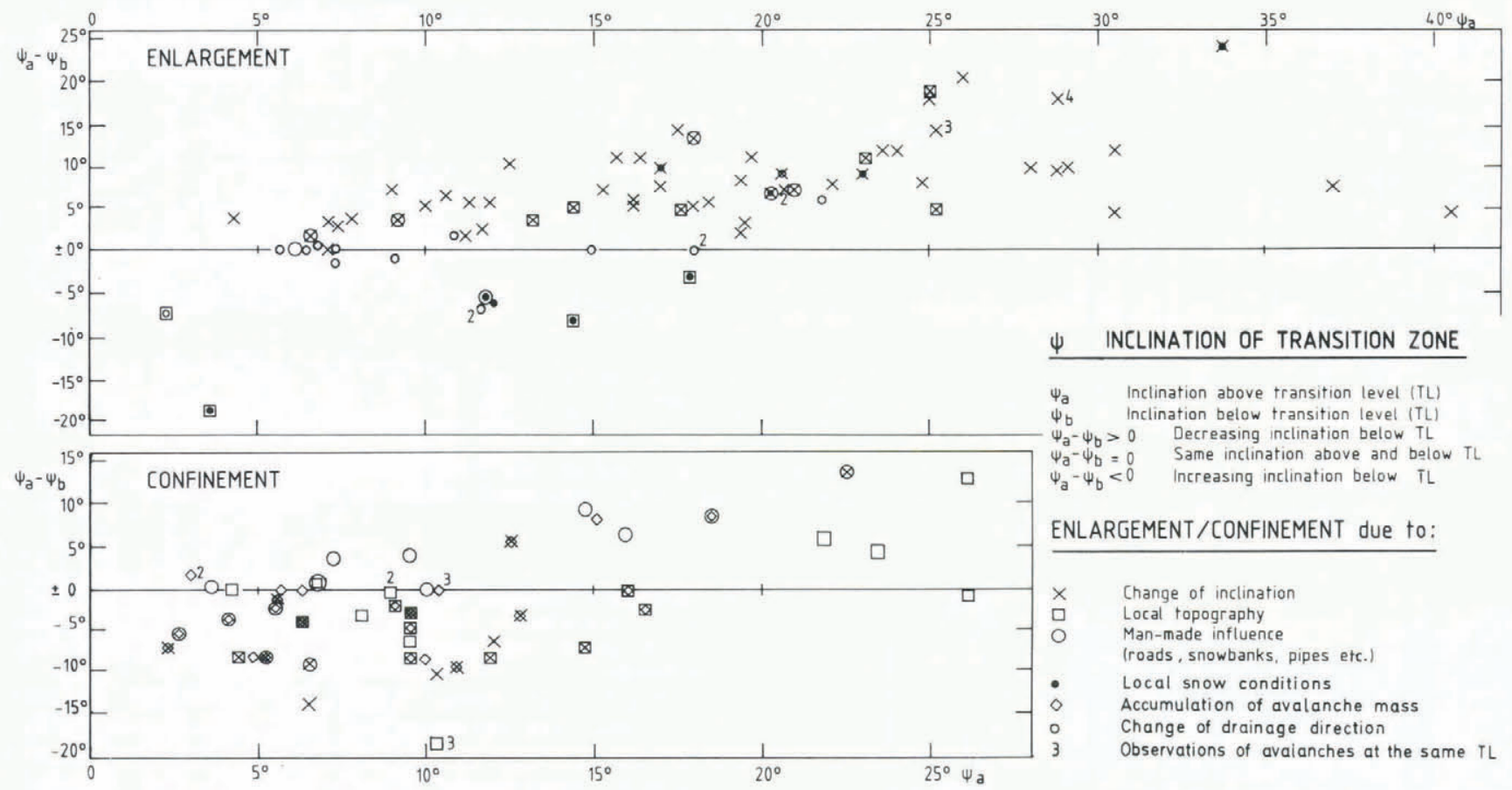

Fig.4. Factors influencing enlargement and confinement of track. The signature of the observations defines the main factors of influence. The location of the signature defines the gradient above the transition level (TL) and change of gradient at this level.

however, from substantial precipitation during a few periods of $4-6$ days to almost continual light snowfall. The maximum daytime temperature during these periods very seldom exceeded $0^{\circ} \mathrm{C}$, and preciptation hardly ever fell on these days. Consequently, a strong temperature gradient formed a weak cohesionless snowpack of coarse grains with depth hoar at the base. Such long-lasting low temperature periods are rather unusual for the districts of Western and Northern Norway where three of these four avalanche situations occurred.

Weather conditions prior to the remaining four avalanche situations were characterized by repeated changes between snowfall, rain, and cold and dry weather, thereby forming hard layers or crusts of ice on the ground or in the snow cover. These changes caused in some locations a steady increase in snow height with different degrees of stability, while in other places the climatic variations resulted in frequent periods without snow cover. As a result of these circumstances the rain nearly always fell on cohesionless new snow, and in some areas the ground itself was definitely not frozen when the avalanches occurred. The observed local differences were due to the local fluctuations of the $0^{\circ} \mathrm{C}$ isotherm and variations in the duration of mild weather.
The current weather situations at eight selected NMI-stations during the avalanche periods described, are illustrated in Figure 6. Temperature above $0^{\circ} \mathrm{C}$ is a necessary condition for slush avalanche release. Heavy rainfall on cohesionless new snow immediately before release was otherwise the most striking feature. Only one exception, caused by intense thaw in the spring, was observed. When avalanches were released in areas with coarse grained snow cover, developed during the period of low temperature, the starting zones had, during the previous 24 hours, received $70-100 \%$ of the recorded daily maximum precipitation for the month. The amount of precipitation for the previous three days was $7-10$ times higher than the three-day mean based on the recorded monthly normal. Corresponding values for the avalanche situations characterized by repeated changes between snowfall, rain, and cold and dry weather, were $40-60 \%$ and $3-6$ times of the mean monthly normal, respectively.

\section{SLUSH AVALANCHE RELEASE TYPES}

Three main categories of slush avalanche release were identified: 1) Sudden release from crown surface, 2) drainage of snow-embanked, water-saturated snowfields through narrow outlets and 3) rapid headward growth

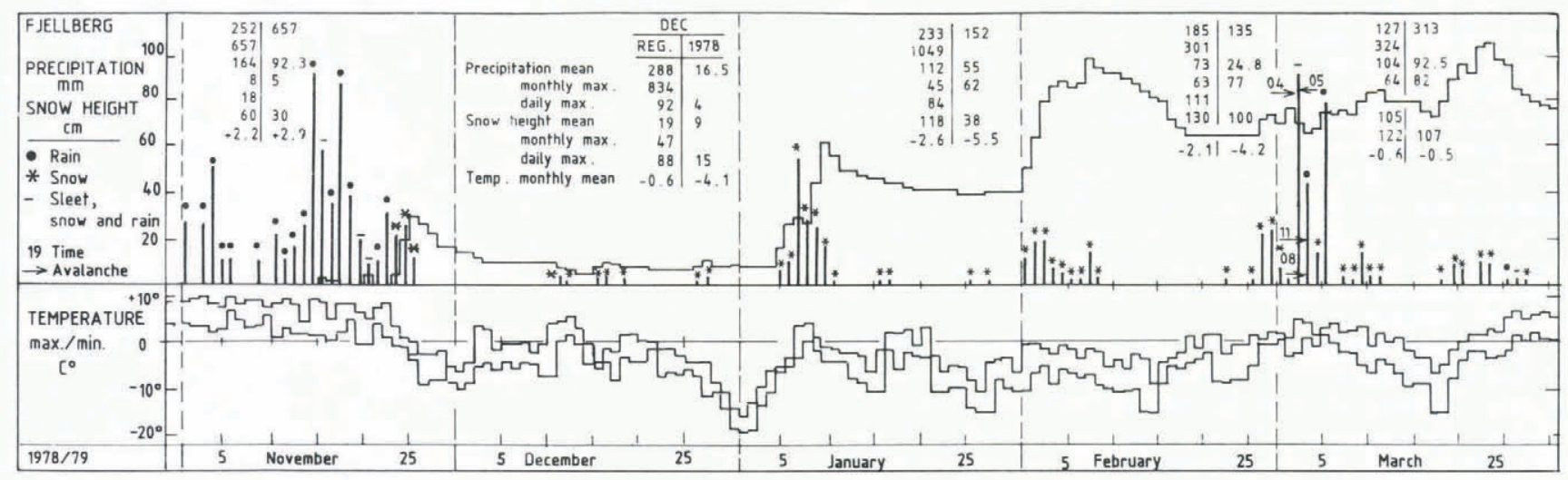

Fig.5. Typical winter weather conditions leading to high slush avalanche risk. Daily records for November to March 1978/79 from the NMI observation station 4603 Ulladal-Fjellberg, Suldal, $382 \mathrm{~m}$ a.s.1. 


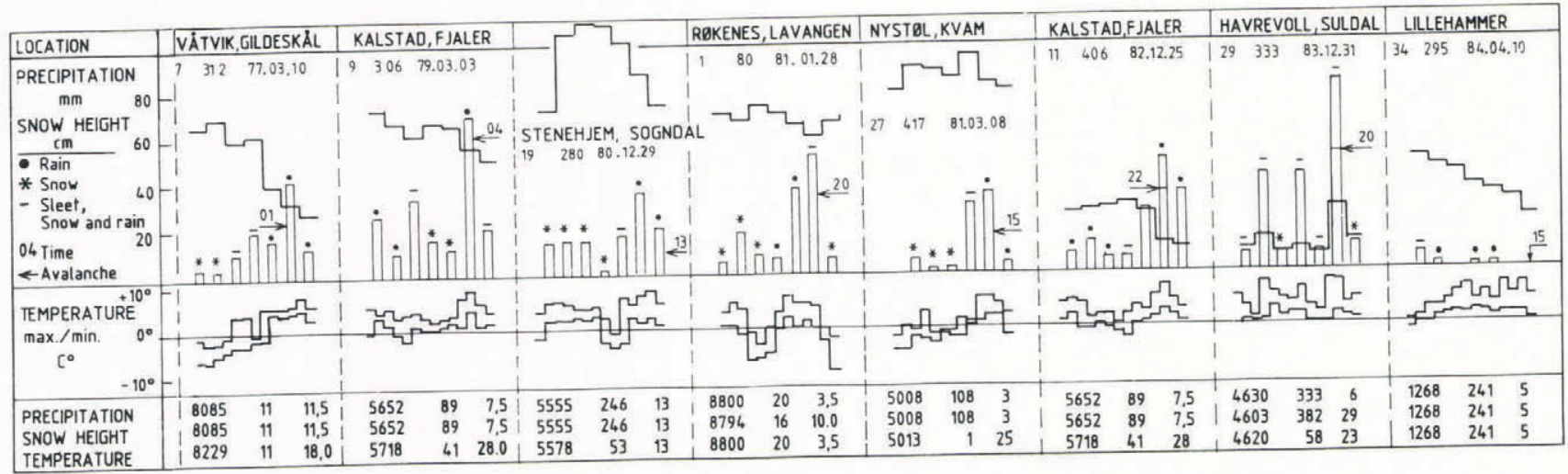

Fig.6. Current weather situation for 8 avalanche situations. Top: Location and municipality, avalanche no., $\mathrm{m}$ a.s.l. of crown surface and date of release. Bottom: NMI observation station no., $\mathrm{m}$ a.s.l. and distance $(\mathrm{km})$ from avalanche site.

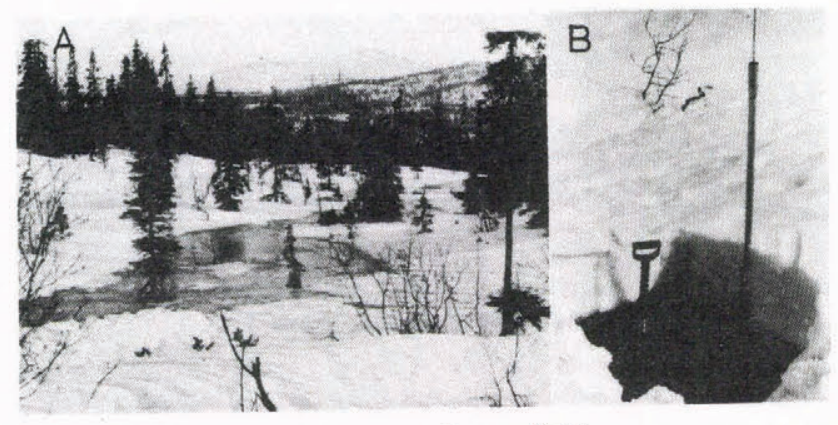

Fig.7. A. Sloping water-saturated snowfield.

B. Water level in snowpack, $100 \mathrm{~cm}$. (Photography by the author)

from the point of first release. In drainage channels the initial point of release normally coincides with the crown surface. The second type obviously merges with bowl-like starting zones, while the third category reflects the release mechanism of avalanches from two bogs and one shallow depression (Table 1). This might as well describe the process of avalanche release on three sloping rock surfaces. Release at successively higher levels along the same drainage channel within short intervals, were also observed.

\section{CONCLUDING REMARKS}

Slush avalanches have primarily been reported from uninhabited arctic and mountainous regions. In Norway slush avalanches are well known phenomena that may be imposed on everyday life. Most commonly they comprise a part of the process of break-up of small drainage channels and streams, but may also start from inclined bogs, depressions and open slopes. Snow-embanked, water-saturated snowfields and lakes are other potential starting zones.

Weak cohesionless snowpack of coarse grains, and hard layers or crusts of ice in snow cover or on the ground, are identified as critical conditions for slush avalanche release. Intense rainfall on cohesionless new snow on these substrata was the most striking feature of the current weather situation.

Snow cover instability results from basal accumulation of water enhanced by the presence of an impermeable icy layer, a rock surface or frozen ground. Intense thaw in spring may also produce more meltwater than can drain through the snow and thus cause release of slush avalanches.

Water-saturation of snow cover is of ten indicated by the appearance of a marked blue-grey colour on the surface. Density of slush is near to $1000 \mathrm{~kg} / \mathrm{m}^{3}$, and the bearing capacity almost nil (Figure 7). Both stability conditions and release mechanisms for water-saturated snowpack will be further investigated in our future research program.

The slush avalanches investigated do not represent a statistical sample. However, it is assumed that the most recurring geomorphic and morphological characteristics of starting zones and tracks are represented.

Finally, it seems natural to stress the serious damage even the smallest slush avalanches may cause to man and property. The knowledge of the influence of seemingly insignificant terrain features and channel irregularities on the avalanche release and motion, should be applied when evaluating the potential damage of slush avalanches.

\section{ACKNOWLEDGEMENTS}

The author is much indebted to the Norwegian Meteorological Institute, which put climatic data at his disposal, and also to the members of the Avalanche Section at NGI for practical help and many valuable comments concerning the manuscript.

\section{REFERENCES}

Barthel K, Bakkeh $\phi i$ S, Lied K 1981 Analyse av vaersituasjonen $\mathrm{i}$ to sn $\phi$ skredsituasjoner pả Vestlandet i 1979. [Meteorological situations during two avalanche situations in Western Norway 1979]. Norges Geotekniske Institutt Rapport 58302-24: 52pp

Luckman B H 1977 The geomorphic activity of snow avalanches. Geografiska Annaler 59A: 31-48

Nobles L H 1966 Slush avalanches in northern Greenland and the classification of rapid mass movements. Publication No 69 de l'Association Internationale d'Hydrologie Scientifique: 267-272

Nord $\varnothing$ J, Hjortnaes K 1966 Statistical studies of precipitation on local, national and continental scales. Geophysica Norvegica 16(12): 46pp

Rapp A 1960 Recent developments of mountain slopes in Karkevagge and surroundings, northern Scandinavia. Geografiska Annaler 42: 73-200

Raup H M 1971 Miscellaneous contributions on the vegetation of the Mesters Vig District, Northeast Greenland. Meddelelser om Grónland 194(2): 105pp 